\title{
Обзор моделей оценки ставки восстановления по корпоративным облигациям
}

\begin{abstract}
Антонова Е.H. ${ }^{25}$
Более точный расчет достаточности капитала банков является одним из требований Базельского комитета по банковскому надзору, изложенных в Базель II. Данная цель достигается, в том числе за счет увеличения точности расчета ставки восстановления по долговым обязательствам, равной единице, за вычетом доли потерь в случае дефолта. Настоящая статья посвящена систематизащии факторов, влияющих на ставку восстановления по корпоративным облигачиям, и обзору моделей ее оценки.
\end{abstract}

$J E L: G 32$

Ключевые слова: ставка восстановления, дефолт, уровень потерь при наступлении дефолта, корпоративные облигащии

\section{Введение}

Ставка восстановления является одним из ключевых параметров оценки возможных потерь при наступлении дефолта по корпоративной облигации наряду с вероятностью дефолта и подверженностью риску при наступлении дефолта. Она показывает, какую долю привлеченных средств эмитент возвращает владельцу облигации в случае ее дефолта. Однако способам прогнозирования ставки восстановления, в отличие от оценки вероятности дефолта, долгое время не уделялось достаточного внимания в научных исследованиях.

Довольно часто на практике ставка восстановления оценивается с помощью статистических таблиц, составленных на основе наблюдений восстановления в прошлом в разрезе уровня старшинства в структуре долговых обязательств эмитента. Основанные на исторических данных, статистические таблицы не учитывают текущие характеристики эмитента и современную экономическую среду, в которой он осуществляет хозяйственную деятельность. Точность оценки также невысока, о чем свидетельствует широкий разброс значений ставки восстановления, в том числе при учете уровня старшинства облигации. Медианные значения и границы первого и третьего квартиля ставки восстановления по корпоративным облигациям в зависимости от уровня старшинства представлены на рисунке 1.

\footnotetext{
${ }^{25}$ Аспирантка НИУ ВШЭ по специальности «Финансы и кредит».
} 


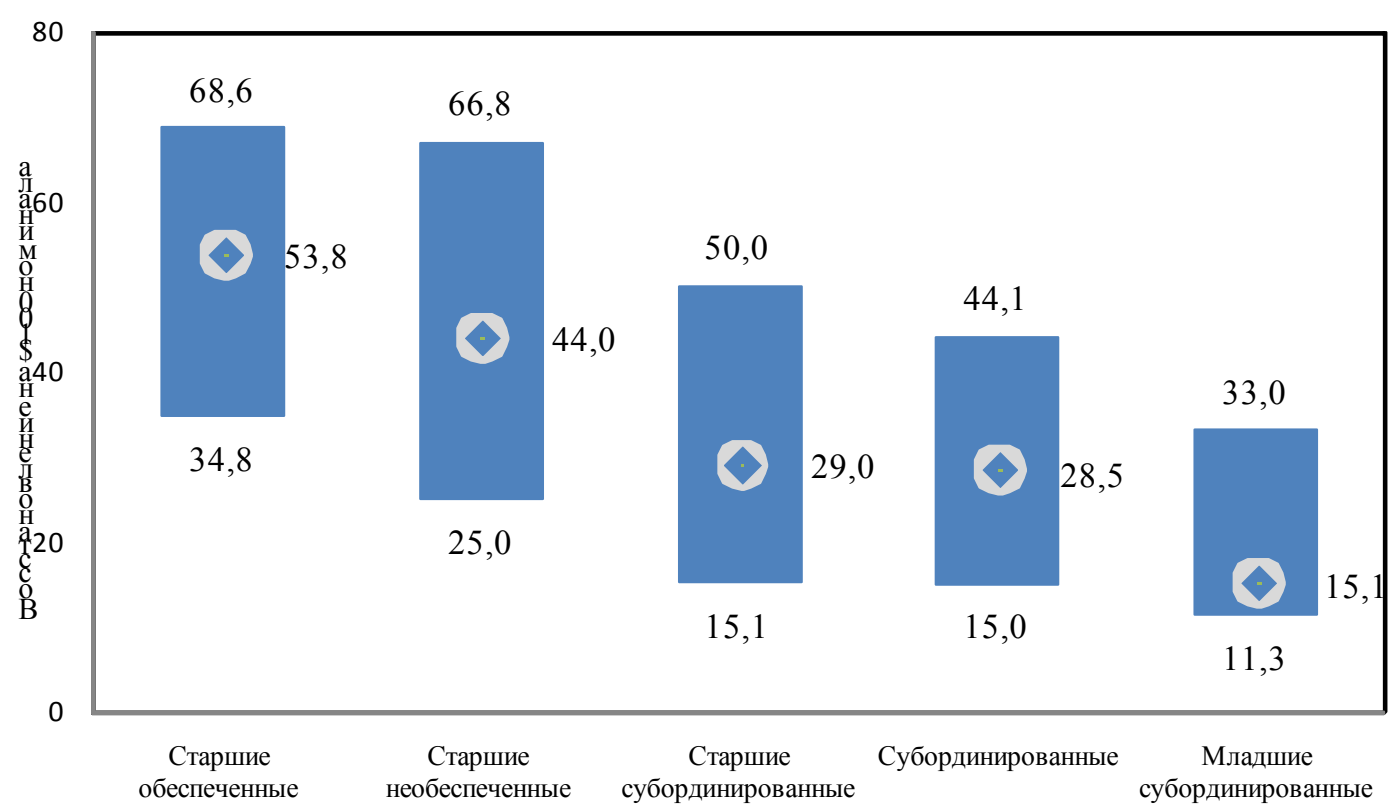

Рисунок 1. Медианные значения и границы первого и третьего квартиля средней ставки восстановления в зависимости от старшинства облигаций, выпущенных с 1981 по 2000 год, по выборке из 2958 наблюдений.

Источник: Moody's Investors Service (Hamilton, 2000).

В свою очередь, требования Базельского комитета по банковскому надзору, изложенные в Базель II, нацелены на более точный расчет достаточности капитала банков. Данная цель достигается в том числе за счет увеличения точности расчета ставки восстановления. Базель II предусматривает дальнейшее усовершенствование регулятивных требований к капиталу посредством применения продвинутого подхода на основе внутренних рейтингов. В соответствии с данным подходом банкам предоставляется возможность применять собственные модели для оценки основных компонентов кредитного риска, в том числе ставки восстановления.

В первой части данной статьи проводится систематизация факторов, влияющих на ставку восстановления. Во второй части рассмотрены два метода, с помощью которых оценивается ставка восстановления, а именно регрессионные модели и класс моделей, основанных на модели Мертона.

\section{Систематизация факторов, влияющих на ставку восстановления}

Вследствие возросшего интереса к прогнозированию ставки восстановления ряд академических и практических исследований, посвященных анализу ее характеристик, был опубликован за последние 15 лет. Исследование Шурманн (Schuermann, 2004) обобщает накопленные знания о ставке восстановления и иллюстрирует их на основе базы данных Moody's Default Risk Service Database, содержащей данные за период 1970-2003 годов. На дату проведения исследования база содержала информацию о 2958 дефолтах по корпоративным облигациям и кредитам, из которых ставка восстановления была известна по 2025 долговым обязательствам, причем 88\% обязательств было выпущено в США. Были получены следующие результаты:

- Функция распределения ставки восстановления имеет вид бимодального распределения: ставка восстановления принимает с повышенной вероятностью либо низкое значение - 20-30\%, либо высокое - 70-80\%. Таким образом, использование среднего значения ставки восстановления приводит к неточным результатам.

- Старшинство и обеспечение по обязательствам являются главными факторами, определяющими значение ставки восстановления при наступлении дефолта. При 
прочих равных условиях, чем выше качество обеспечения и выше ее старшинство, тем выше ставка восстановления. Исторические наблюдения подтверждают, что обеспеченные обязательства, находясь на вершине структуры долговых обязательств, имеют более высокую ставку восстановления.

- Изменение ставки восстановления во времени характеризуется цикличностью. Ставка восстановления имеет тенденцию к понижению при наступлении рецессии. В период рецессии среднее значение ставки восстановления по используемой выборке на треть ниже, чем в период экономического подъема.

- Отраслевая принадлежность заемщика оказывает существенное влияние на ставку восстановления. Отрасли экономики, с высокой долей основных активов в структуре баланса эмитента, в частности коммунальные услуги, характеризуются более высокими ставками восстановления, чем отрасли предоставления услуг, в которых зависимость от основных средств ниже.

- Сумма подверженности риску при наступлении дефолта не оказывает сильного влияния на ставку восстановления.

Обобщая результаты предшествующих исследований (Varma et al., 2004; Acharya et al.,2003), факторы, влияющие на ставку восстановления, можно разделить на следующие группы:

- старшинство облигации;

- тип дефолта;

- специфические для компании факторы;

- специфические для отрасли факторы;

- макроэкономические факторы;

- прочие факторы.

\section{Стариинство и обеспечение облигации}

Старшинство и обеспечение по облигации являются факторами, специфическими для конкретной облигации. Предшествующие эмпирические исследования (Varma et al., 2004) установили, что эти характеристики имеют наибольшую значимость в прогнозировании ставки восстановления. Прочие характеристики облигации, такие как размер купона, срок до погашения и объем эмиссии, не оказывают существенного влияния на ее величину (Acharya et al., 2003).

\section{Стариинство}

Старшинство облигации определяет приоритетность выплат по данному облигационному выпуску по отношению к прочим финансовым обязательствам эмитента перед кредиторами и владельцами. В большинстве развитых стран мира, в том числе в США, существует «правило абсолютного приоритета», согласно которому в случае ликвидации заемщика кредиторы-владельцы старших обеспеченных обязательств имеют приоритет перед всеми остальными кредиторами и акционерами. Таким образом, в случае ликвидации компания в первую очередь полностью погашает обязательства перед кредиторами владельцами старших обеспеченных обязательств, и только после этого погашаются обязательства перед остальными кредиторам в порядке снижения старшинства обязательств. В последнюю очередь удовлетворяются требования владельцев компании. Соответствие структуры старшинства обязательств компании с законодательством США показано на рисунке 2. 


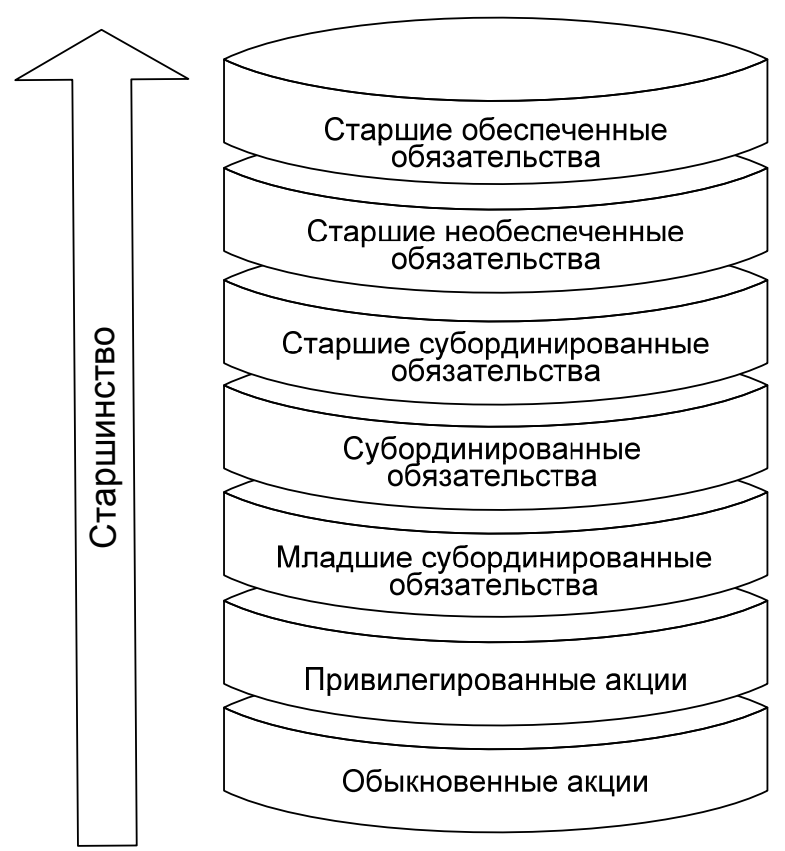

Рисунок 2. Старшинство обязательств компании и приоритетность выплат

Источник: (Schuermann, 2004).

Эмпирические исследования показывают, что при прочих равных условиях обязательства с более высоким приоритетом выплат характеризуются более высокой ставкой восстановления. В таблице 1 представлены средние и медианные значения ставок восстановления в зависимости от уровня старшинства из исследования Шурманн (Schuermann, 2004), проведенного на основе выборки из 2025 наблюдений ставки восстановления по корпоративным облигациям и кредитам.

Таблица 1

Средние значения ставок восстановления в зависимости от старшинства

\begin{tabular}{|l|l|l|l|}
\hline \multicolumn{1}{|c|}{ Уровень старшинства } & \multicolumn{1}{c|}{$\begin{array}{c}\text { Среднее } \\
\text { значение }\end{array}$} & $\begin{array}{c}\text { Медианное } \\
\text { значение }\end{array}$ & $\begin{array}{l}\text { Количество } \\
\text { наблюдений }\end{array}$ \\
\hline Старшие обеспеченные обязательства & 54,26 & 53,50 & 433 \\
\hline Старшие необеспеченные обязательства & 38,71 & 30,75 & 971 \\
\hline $\begin{array}{l}\text { Старшие субординированные } \\
\text { обязательства }\end{array}$ & 28,51 & 23,00 & 260 \\
\hline Субординированные обязательства & 34,65 & 30,29 & 347 \\
\hline $\begin{array}{l}\text { Младшие субординированные } \\
\text { обязательства }\end{array}$ & 14,39 & 13,00 & 12 \\
\hline
\end{tabular}

Источник:Moody's Default Risk Service Database (Schuermann, 2004).

Tип обеспечения

Наличие обеспечения неразрывно связано со старшинством обязательства и существенно влияет на ставку восстановления. Например, по данным таблицы 1 , наличие обеспечения у старших обязательств увеличивает среднюю ставку восстановления с 38,71 до $54,26 \%$. Тип обеспечения также имеет существенное влияние на ставку восстановления. Чем выше ликвидность обеспечения, тем выше ставка восстановления. Исторические данные международного рейтингового агентства Standard and Poor's также подтверждают зависимость ставки восстановления от типа обеспечения. Средняя ставка восстановления, 
рассчитанная на основе данных по 993 обеспеченным обязательствам: для обязательств, обеспеченных ликвидными активами, составляет 93\% (78 наблюдений); для обязательств, обеспеченных основными активами, - 70\% (718 наблюдений), для обязательств, обеспеченных прочими активами, - 57\% (197 наблюдений).

\section{Тип дефолта}

Ряд исследований посвящен оценке ставки восстановления в зависимости от типа дефолта, например Варма (Varma et al., 2004). В случае невыполнения заемщиком своих обязательств по обслуживанию долга кредитор вправе требовать возмещения понесенных потерь посредством судебного разбирательства или попытаться реструктурировать долг в ходе внесудебных переговоров с заемщиком. В работе Франкс и Тороус (Franks, 1994) показано, что по обязательствам компаний, которые проводят внесудебную реструктуризацию после наступления дефолта, напрямую договариваясь с кредиторами, ставка восстановления значительно выше, чем по обязательствам компаний, проходящих формальную процедуру реорганизации.

В исследовании Варма (Varma et al., 2004), посвященном анализу дефолтов по кредитам и облигациям американских корпораций, рассматривается шесть типов дефолтов: банкротство в соответствии с главой 11 и главой 7, реструктуризация долга, просрочка платежа купона, просрочка платежа номинала и задержка платежей в рамках льготного периода $^{26}$. Глава 11 - это одна из глав «Закона о банкротстве» США, которая позволяет проводить реорганизацию компании в случае наступления дефолта по ее обязательствам. В свою очередь в главе 7 изложена процедура проведения ликвидации компании. На рисунке 3 показана средняя ставка восстановления в зависимости от типа дефолта. Наименьшее значение ставка восстановления принимает при ликвидации компании, что объясняется высокими прямыми и косвенными издержками, связанными с проведением процедуры банкротства. Ставка восстановления практически не отличается в случае просрочки платежа номинала, реструктуризации долга и задержки платежей в рамках льготного периода.

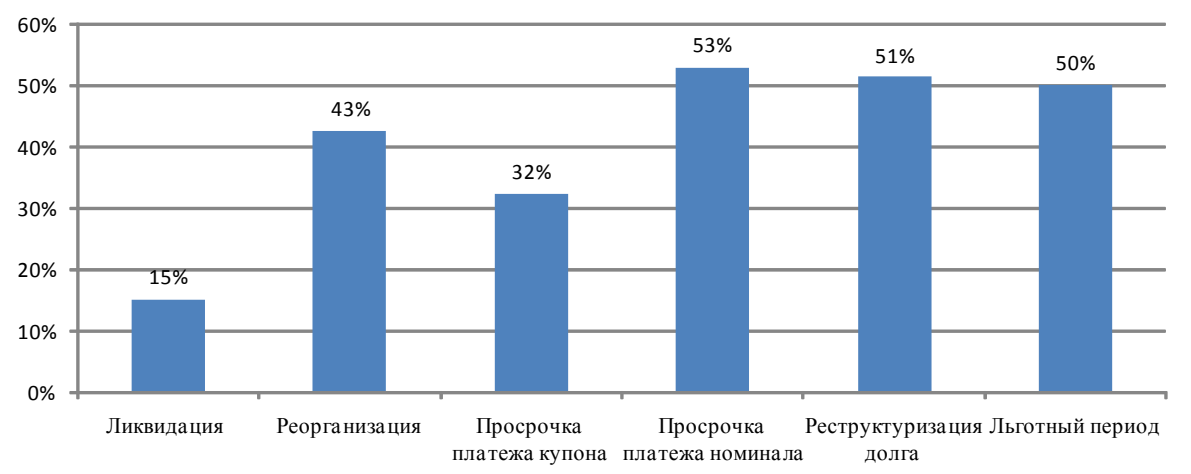

Рисунок 3. Средняя ставка восстановления в зависимости от типа дефолта Источник: Moody's Investor Service (Varma et al., 2004).

\section{Специфические для компании факторы}

\section{Продолжительность реструктуризациии/процедуры банкротства}

Продолжительность реструктуризации/процедуры банкротства после наступления дефолта по обязательствам влияет на ставку восстановления по причине высоких прямых и косвенных издержек, которые несет компания при прохождении процедуры банкротства. В работе Ачарии (Acharya et al., 2003) показано, что увеличение продолжительности

\footnotetext{
26 Льготный период - это период после установленной даты выплаты купонного дохода или погашения ценной бумаги, в течение которого инвесторы не имеют права предпринимать действий по взысканию неисполненных обязательств.
} 
банкротства на один год приводит к снижению ставки восстановления на 5\%.

\section{Долговая подушка}

Данный показатель рассчитывается как отношение суммы долгового обязательства, по которому происходит дефолт, к сумме обязательств, младших по отношению к данному обязательству. Например, долговая подушка для облигаций из старшего необеспеченного класса обязательств компании рассчитывается как отношение суммы данного облигационного займа к сумме всех облигаций младше старших необеспеченных обязательств и привилегированных акций.

В исследовании рейтингового агентства Standard and Poor's (VandeCastle, 1999) на основе анализа исторических данных делается вывод о том, что облигации с большей долей подчиненных им обязательств имеют более высокие ставки восстановления. В свою очередь в исследовании Варма (Varma et al., 2004) показатель долговой подушки также оказался статистически значимым в объяснении ставки восстановления. Для облигаций, у которых показатель долговой подушки относился к группе с низкими значениями (менее 15\%), средняя ставка восстановления составила около $31 \%$, тогда как в группе с высоким показателем долговой подушки (более 60\%) - около 50-55\%.

\section{Финансовый рычаг}

Показатель финансового рычага рассчитывается как отношение суммы долговых обязательств к собственному капиталу компании. Влияние финансового рычага на ставку восстановления неоднозначно. С одной стороны, увеличение показателя финансового рычага связанно с увеличением заемных средств и приводит к тому, что при ликвидации компании выручка от реализации ее активов с меньшей вероятностью будет достаточна для осуществления выплат по всем обязательствам компании. В данном случае влияние роста показателя финансового рычага на ставку восстановления отрицательно.

С другой стороны, компании с высокой долей долговых обязательств подвергаются более тщательной предварительной проверке со стороны кредиторов при выдаче кредитов, что предполагает независимую оценку и большую уверенность в способности компании обслуживать обязательства. Иное объяснение предлагает теория отношений «принципал агент». Владельцы компании, как правило, неспособны осуществлять полный контроль за деятельностью менеджеров по причине информационной асимметрии, так как менеджеры компании имеют больше возможностей для сбора, обработки и интерпретации информации о результатах хозяйственной деятельности компании. В такой ситуации владельцы компании могут быть заинтересованы в увеличении долговых обязательств компании, чтобы усилить мониторинг за действиями менеджеров посредством дополнительного контроля со стороны кредиторов. Таким образом, высокий уровень финансового рычага может свидетельствовать о том, что в компании работает более эффективная система мониторинга, что может иметь влияние на повышенное возмещение по обязательствам компании.

Неоднозначность влияния финансового рычага на значение ставки восстановления нашла отражение в эмпирических исследованиях. В модели Изворски (Izvorski, 1997) и в одной из спецификаций модели Ачарии (Acharya et al., 2003) коэффициент при показателе финансового рычага в мультифакторных моделях оказался положительным. В свою очередь в исследовании Варма (Varma et al., 2004) средняя ставка восстановления в группе с уровнем финансового рычага ниже $35 \%$ составляет 3,2 , тогда как в группе с уровнем финансового рычага выше $65 \%--1,7$, что свидетельствует об отрицательной зависимости между ставкой восстановления и финансовым рычагом. 
Отночение рыночной стоимости активов к бухгалтерской стоимости

Отношение рыночной стоимости активов компании, также известное как «показатель Q», рассчитывается как сумма рыночной стоимости капитала и бухгалтерской стоимости обязательств к бухгалтерской стоимости активов компании. Данный показатель позволяет сравнивать рыночную оценку компании со стоимостью, указанной в финансовых отчетах. Высокий показатель говорит о том, что участники рынка положительно оценивают перспективы компании и ее способность генерировать денежные потоки в будущем и устанавливают надбавку к балансовой стоимости компании. Таким образом, высокое значение показателя Q оказывает положительное влияние на ставку восстановления, что подтверждается эмпирическими исследованиями.

B работе Варма (Varma et al., 2004) показатель Q имеет положительную корреляцию со ставкой восстановления. Компании с показателем Q выше среднего значения по рынку за год до наступления дефолта имели более высокие ставки восстановления. Отчасти это может быть объяснено тем, что, несмотря на дефолт, участники рынка продолжают верить в потенциал роста компании и ее способность генерировать прибыль.

\section{Отночение основных активов к общим активам компании}

Оценка ликвидационной стоимости основных активов является важным этапом в оценке уровня возмещения по обязательствам заемщика, так как в случае дефолта выплаты кредиторам могут осуществляться в том числе за счет реализации основных активов. Под основными активами понимаются активы компании, используемые в производственном процессе, со сроком службы, как правило, свыше года, которые не предназначены для продажи в рамках основной хозяйственной деятельности: например, земля, здания, оборудование и пр. Однако влияние отношения основных активов к общим активам компании на ставку восстановления также неоднозначно. С одной стороны, высокая доля основных активов свидетельствует о материальной оснащенности компании и о ведении реальной хозяйственной деятельности, а также о более высокой ликвидационной стоимости компании. Положительная зависимость подтверждается эмпирическими исследованиями (Varma et al., 2004): компании из группы с высокими показателями имеют ставки восстановления на $25 \%$ больше, чем компании в группе с низкими показателями.

С другой стороны, высокая доля основных средств в валюте баланса может свидетельствовать об их низкой ликвидационной стоимости. В условиях финансовых сложностей компании снижают капитальные инвестиции и замедляют замещение основных активов, что приводит к их ускоренному устареванию. В этом случае между ставкой восстановления и долей основных средств в общих активах компании может наблюдаться отрицательная зависимость. Быстрая реализация основных активов компании в случае ликвидации возможна только с существенной скидкой ввиду их отраслевой специализации и ограниченного числа потенциальных покупателей. В мультифакторных моделях Изворски (Izvorski, 1997) и Ачарии (Acharya et al., 2003) коэффициент при показателе доли основных средств в валюте баланса имеет отрицательный знак.

\section{Рентабельность продаж}

Рентабельность продаж компании, рассчитываемая как отношение прибыли до налогов, процентов и амортизации (EBITDA) к ее выручке за год до наступления дефолта, характеризует платежеспособность компании. Чем выше рентабельность продаж, тем у компании больше возможностей расплачиваться по долговым обязательствам. С точки зрения экономической логики, между ставкой восстановления и рентабельностью продаж существует положительная корреляция, что подтверждается эмпирическими исследованиями 
(Acharya et al., 2003).

\section{Доходность акций компании}

Динамика доходности акций компании за год до наступления дефолта, с одной стороны, отражает ожидания инвесторов относительно потенциала роста компании, а с другой - свидетельствует о ее рискованности. В исследовании Bapмa (Varma et al., 2004) и Ачарии (Acharya et al., 2003) обнаружена положительная зависимость между доходностью акций компании за год до наступления дефолта и ставкой восстановления. Согласно данным исследованиям, высокая доходность по акциям свидетельствует о финансовой устойчивости компании и способности лучше справляться с финансовыми затруднениями.

\section{Специфические для отрасли факторы}

\section{Средняя доходность акичй по отрасли}

Средняя доходность акций по отрасли характеризует динамику развития отрасли. В исследовании Ачарии (Acharya et al., 2003) используется усредненная доходность акций компаний отрасли за год, предшествующий дефолту. Спад в отрасли определяется как снижение средней доходности по отрасли более чем на 30\%. Было установлено, что в случае спада в отрасли ставка восстановления на 10-20\% ниже, чем в нормальных экономических условиях. Работа Варма (Varma et al., 2004) подтвердила, что связь между ставкой восстановления и средней доходностью отрасли является положительно монотонной.

\section{Показатель $Q$ по отрасли}

Одной из возможных интерпретаций показателя Q по отрасли является потенциал роста отрасли. В исследовании Ачарии (Acharya et al., 2003) и Варма (Varma et al., 2004) данный показатель рассчитывается как среднее значение показателей Q компаний, входящих в отрасль. Между ставкой восстановления и среднеотраслевым значением Q наблюдается положительная зависимость. Таким образом, статистическая значимость данного фактора подчеркивает значение перспектив развития отрасли в целом для объяснения величины ставки восстановления.

\section{Индекс концентрациии}

В качестве показателя концентрации в исследованиях Изворски (Izvorski, 1997), Варма (Varma et al., 2004) и Ачарии (Acharya et al., 2003) используется индекс Херфиндаля, который рассчитывается как сумма рыночных долей компаний в отрасли, возведенных в квадрат. В данных работах рыночная доля измеряется посредством доли продаж компании в отрасли. Чем выше значение индекса концентрации Херфиндаля, чем выше концентрация и ниже конкуренция в отрасли.

(1)

$$
H H=\sum_{i=1}^{N}\left(\frac{s_{i}}{\sum_{i=1}^{N} s_{i}}\right)^{2},
$$

где $S_{i}$ - продажи компании $i$ в отрасли, состоящей из $N$ компаний.

Ликвидационная стоимость основных активов ниже в отраслях с высокой концентрацией, поскольку количество потенциальных покупателей основных средств при ликвидации ограничено. Поэтому чем выше степень концентрации в отрасли, тем меньше 
ставка восстановления. Данная экономическая логика проверяется в эмпирических исследованиях Изворски, Варма и Ачарии. Во всех работах была установлена положительная взаимосвязь между ставкой восстановления и индексом концентрации, однако только в работе Изворски она является статистически значимой.

\section{Уровень ликвидности в отрасли}

В исследовании Ачарии (Acharya et al., 2003) влияние уровня ликвидности в отрасли на ставку восстановления оценивается с помощью двух показателей. Первый показатель определяется как медианное значение коэффициентов срочной ликвидности, рассчитанных для всех компаний отрасли. Коэффициент срочной ликвидности равен отношению текущих активов за вычетом материально-производственных запасов к текущим обязательствам компании. Второй показатель определяется на основе медианного значения коэффициентов покрытия долга, рассчитанных для всех компаний отрасли и равных отношению прибыли до амортизации, процентов и налогов (EBITDA) к процентным выплатам по долгу (debt coverage). Зависимость ставки восстановления от первого показателя положительна и статистически значима. Исследование Ачарии не подтверждает статистическую значимость второго показателя на ставку восстановления.

\section{Специиализащия основных активов в отрасли}

В исследовании Ачарии (Acharya et al., 2003) специализация основных активов компании определяется как отношение бухгалтерской стоимости машин и оборудования к совокупным активам. Показатель специализации активов в отрасли рассчитывается как медианное значение индивидуальных показателей, рассчитанных для компаний в данной отрасли.

Влияние специализации основных активов на ставку восстановления оценивается в нормальных экономических условиях и в условиях спада. Наличие спада в отрасли определяется как снижение средней доходности по отрасли более чем на $30 \%$ за год, предшествующий дефолту. Для каждой отраслевой группы были рассчитаны средние и медианные значения ставки восстановления. В таблице 2 показана корреляция между ставкой восстановления и степенью специализации основных активов в отрасли в зависимости от наличия или отсутствия спада в отрасли.

Таблица 2

Зависимость между ставкой восстановления и степенью специализации активов отрасли

\begin{tabular}{|c|c|c|c|}
\hline Корреляции & $\begin{array}{l}\text { Отсутствие спада } \\
\text { отрасли }\end{array}$ & $\begin{array}{l}\text { Наличие } \\
\text { отрасли }\end{array}$ & спада в \\
\hline $\begin{array}{l}\text { Между медианныли значениями } \\
\text { специализаџии активов } \\
\text { ставков восстановления }\end{array}$ & $-0,015$ & $-0,763^{*}$ & \\
\hline $\begin{array}{l}\text { Между средними значениями } \\
\text { специализацией активов } u \\
\text { ставков восстановления }\end{array}$ & 0,200 & $-0,626^{* *}$ & \\
\hline
\end{tabular}

* Значимость показателя на уровне $1 \%$.

** Значимость показателя на уровне $5 \%$.

Источник: (Acharya et al., 2003).

В случае отсутствия спада в отрасли коэффициент корреляции нестабилен и не является статистически значимым. Напротив, в случае спада в отрасли корреляция между ставкой восстановления и степенью специализации активов отрицательна и статистически значима. 


\section{Отраслевая принадлежность}

В ряде эмпирических исследований устанавливается влияние отраслевой принадлежности компании на ставку восстановления. В таблице 3 показаны средние значения ставки восстановления по различным отраслевым группам, рассчитанные в исследовании Альтмана и Кишор (Altman, Kishore, 1996). Исследование проводилось по выборке, состоящей из 696 наблюдений дефолтов по корпоративным облигациям эмитентов США, произошедшим с 1971 по 1995 год. Авторы выделили 18 групп, состоящих из сходных отраслей.

Таблица 3

Средние значения ставок восстановления в зависимости от отраслевой группы

\begin{tabular}{|c|c|c|}
\hline Отраслевая группа & $\begin{array}{c}\text { Ставка } \\
\text { восстановления в \% } \\
\text { от номинала } \\
\end{array}$ & $\begin{array}{l}\text { Количество } \\
\text { наблюдений }\end{array}$ \\
\hline Коммунальное хозяйство & 70,47 & 56 \\
\hline $\begin{array}{l}\text { Химическая промышленность, } \\
\text { промышленность, производство } \\
\text { пластмассы }\end{array}$ & 62,73 & 35 \\
\hline $\begin{array}{l}\text { Машиностроение, производство оборудование и } \\
\text { других связанных продуктов }\end{array}$ & 48,74 & 36 \\
\hline $\begin{array}{l}\text { Оказание услуг (перевозки, медицинские услуги, } \\
\text { прачечные и химчистки, ремонт техники) }\end{array}$ & 46,23 & 14 \\
\hline Производство продуктов питания & 45,28 & 18 \\
\hline Оптовая и розничная торговля & 44,00 & 12 \\
\hline $\begin{array}{lc}\text { Прочие } \\
\text { промышленности }\end{array}$ & 42,29 & 20 \\
\hline Казино, развлечения, отели & 40,15 & 21 \\
\hline Производство стройматериалов, металлургия & 38,76 & 68 \\
\hline Транспорт и производство транспортных средств & 38,42 & 52 \\
\hline Телекоммуникации, связь, киноиндустрия & 37,08 & 65 \\
\hline Финансовые услуги & 35,69 & 66 \\
\hline Строительство и недвижимость & 35,27 & 35 \\
\hline $\begin{array}{l}\text { Продажа бытовой техники, продажа мебели, } \\
\text { прочие продажи, продовольственные магазины, } \\
\text { рестораны и кафе }\end{array}$ & 33,16 & 89 \\
\hline $\begin{array}{lcc}\text { Горнодобывающая } & \text { промышленность } & \text { и } \\
\text { нефтегазовая добыча } & & \\
\end{array}$ & 33,02 & 45 \\
\hline Текстильная промышленность & 31,66 & 31 \\
\hline $\begin{array}{l}\text { Деревообрабатывающая, целлюлозно-бумажная } \\
\text { промышленность }\end{array}$ & 29,77 & 11 \\
\hline Больницы и санатории & 26,49 & 22 \\
\hline Среднее значение / Всего наблюдений & 41,00 & 696 \\
\hline
\end{tabular}

Источник: Альтман и Кишор (Altman, Kishore, 1996).

Среднее значение по выборке составляет 41\%. Однако в зависимости от отрасли ставка восстановления принимает значения от 26,49 до $70,47 \%$.

Средняя ставка восстановления, рассчитанная по дефолтам компаний из отрасли коммунального хозяйства, максимальна, что также подтверждается исследованиями Варма (Varma et al., 2004) и Ачарии (Acharya et al., 2003). Данный факт имеет специальное название - «эффект коммунального хозяйства». Он состоит в том, что при учете прочих факторов в 
мультифакторных моделях фактор принадлежности к отрасли не имеет статистически значимого влияния на ставку восстановления, за единственным исключением в случае отрасли коммунального хозяйства.

\section{Макроэкономические факторы}

В данном разделе рассматривается зависимость ставки восстановления от макроэкономических условий. Проведенные исследования выявили, что наиболее значимыми макроэкономическими факторами являются темп роста ВВП, доходность рыночного индекса, спрэды доходности спекулятивных ценных бумаг, страновые особенности и агрегированная частота дефолта.

\section{Темп роста ВВП}

Эмпирическое исследование Фрай (Frye, 2000) подтверждает положительную зависимость между благоприятными макроэкономическими условиями, измеряемыми темпом роста ВВП, и ставкой восстановления. Автор объясняет эту зависимость тем, что макроэкономические условия оказывают существенное влияние на ликвидационную стоимость активов. Исследование Варма (Varma et al., 2004) подтверждает данную взаимосвязь, выявив положительную корреляцию между ставкой восстановления и темпом роста ВВП. Ставка восстановления, рассчитанная по совокупности наблюдений в условиях темпа роста ВВП свыше 4,52\%, превышает на $15 \%$ ставку восстановления в условиях низкого роста ВВП (менее 1,54\%).

\section{Доходность рыночного индекса}

В отличие от темпа роста ВВП, измеряющего экономический рост в прошлом, доходность рыночного индекса является лидирующим индикатором, который характеризует ожидания экономических агентов относительно будущего. Повышенная доходность рыночного индекса свидетельствует об ожидании экономического подъема, в условиях которого восстановление выше.

Согласно исследованию Варма (Varma et al., 2004), средняя ставка восстановления компаний, дефолт по облигациям которых происходил в период повышенной доходности рыночного индекса S\&P500 (свыше 12,1\%), в среднем на 6\% превышает ставку восстановления в случае дефолта в период пониженной доходности рыночного индекса (менее 6\%).

\section{Спред доходности спекулятивных облигаџий}

Спред доходности спекулятивных облигаций является наблюдаемой мерой риска, равной разности между доходностью к погашению спекулятивных и государственных облигаций. Участники рынка требуют повышенного спреда доходности по более рискованным активам, которые характеризуются пониженной ставкой восстановления. Исследование Варма (Varma et al., 2004) подтверждает связь между спредом доходности и ставкой восстановления на основе регрессионного анализа: согласно однофакторным моделям, в случае низких значений спрэда доходности по спекулятивным облигациям (меньше 3,8\%) ставка восстановления на 30\% выше, чем при высоких значениях данного показателя (более 4,8\%).

\section{Страновые особенности}

Оценка влияния страновой принадлежности эмитента облигации на ставку 
восстановления заслуживает внимания по причине юридических различий в процедуре проведения банкротства в разных странах. По наблюдениям Хамильтон и Кантор (Hamilton, Cantor, 2002), ставка восстановления по корпоративным облигациям европейских эмитентов в среднем на 20\% ниже ставки восстановления по корпоративным облигациям в Северной Америке. Однако значимость полученных результатов ограничена недостаточным объемом статистической базы, которая состоит из 34 дефолтов корпоративных облигаций, произошедших за 16 лет, с 1985 по 2001 год, и имеет отраслевую концентрацию в секторе телекоммуникаций. Интерпретация результатов также осложнена тем, что законодательство о банкротстве в Европе стремительно изменялось в рассматриваемый период наблюдений.

\section{Агрегированная частота дефолта}

Взаимосвязь между ставкой восстановления и агрегированной частотой дефолта подтверждается рядом исследований, в том числе в работе Альтмана (Altman et al., 2005). Агрегированная частота дефолта рассчитывается как отношение суммы номиналов либо количества долговых инструментов, по которым произошел дефолт в течение года, к сумме номиналов либо количеству всех долговых инструментов соответствующего класса на начало года.

Исследования рейтинговых агентств подтверждают совпадающую цикличность в поведении средней ставки восстановления и агрегированной частоты дефолта. Рейтинговое агентство Moody's обобщило данные о ставке восстановления и агрегированной частоты дефолта за период с 1987 по 2008 год. Результаты исследования представлены на рисунке 5. В период краха интернет-компаний в 2001 году ставка восстановления снижается ниже среднего значения $(54,5 \%)$, до $41 \%$, а затем возрастает в более благоприятных условиях последующего экономического подъема. Цикличность динамики средней ставки восстановления также подтверждается работами Альтмана (Altman et al., 2001) и Гуптона и Стейна (Gupton, Stein, 2002).

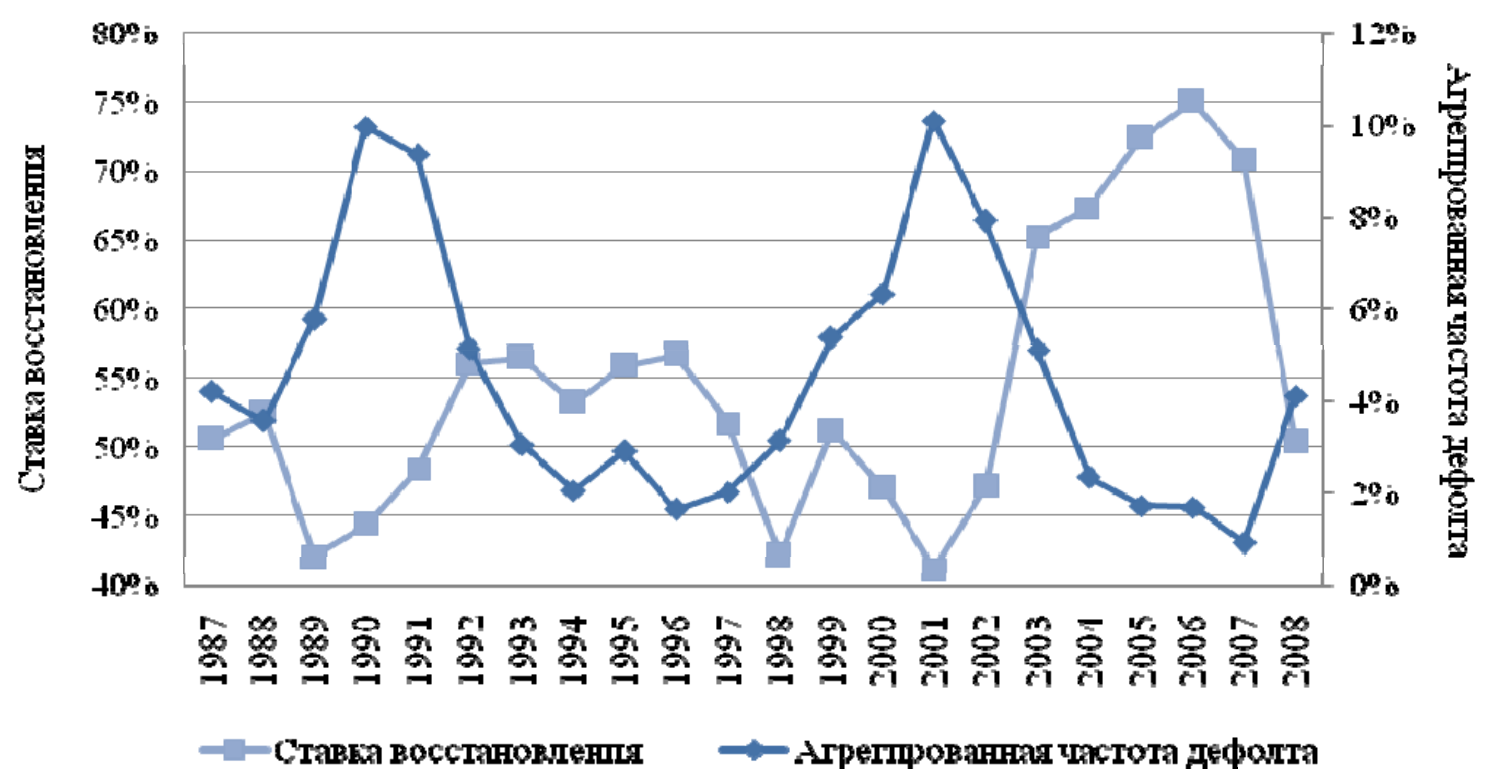

Рисунок 4. Корреляция между ставкой восстановления и агрегированной частотой дефолта по базе данных Moody’s за 1987-2008 годы

\section{Прочие факторы}

Ряд работ посвящен исследованию прочих факторов, не вошедших ни в одну из вышеперечисленных категорий. Например, в исследовании Ковитц и Хан (Covitz, Han, 2004), сотрудников аналитического отдела ФРС США, оценивается влияние на ставку 
восстановления таких факторов, как отсрочка банкротства (default delay) ${ }^{27}$, резкие изменения в стоимости компании (например, в случае выявления мошенничества и фальсификации отчетности), а также издержки, связанные с проведением процедуры банкротства. Однако статистическая значимость полученных результатов либо не нашла подтверждения, либо применима исключительно для специфичного сегмента рынка.

\section{Модели оценки ставки восстановления}

\section{Оценка ставки восстановления с помощью регрессионных моделей}

Повышенное внимание как в академической, так и в практической литературе уделено регрессионным методам оценки ставки восстановления, как наиболее простому инструменту, позволяющему учесть перечисленные выше факторы. В таблице 3 представлены научные исследования, в которых ставка восстановления моделируется с помощью регрессионных моделей. Регрессионные методы применяются на различных уровнях агрегирования данных, а именно на уровне инструмента, эмитента, отрасли и экономики страны в целом. В последних четырех столбцах таблицы показано, какие группы факторов использованы в модели.

В ранней работе Альтмана и Кишор (Altman, Kishore, 1996) используется однофакторная регрессионная модель, однако начиная с работы Изворски (Izvorski, 1997) авторы оценивают ставку восстановления с помощью многофакторных моделей, в которых чаще всего используются факторы из всех четырех групп. Пик исследовательского интереса к факторам, влияющим на ставку восстановления по корпоративным облигациям, приходится на 2000-2005 годы, когда были опубликованы работы Ачарии (Acharya et al.,2003) и Вармы (Varma et al., 2004). Начиная с 2006 года большая часть опубликованных работ посвящена анализу факторов, объясняющих ставку восстановления по кредитам. Однако интерес к оценке ставки восстановления по корпоративным облигациям попрежнему актуален. В июле 2010 года Джейкобс [Jacobs, 2010] опубликовал исследование, в котором ставка восстановления моделируется посредством обобщенной линейной модели.

Таблица 4

Модели оценки ставки восстановления по корпоративным облигациям

\begin{tabular}{|c|c|c|c|c|c|c|c|}
\hline \multirow{2}{*}{ Авторы } & \multirow{2}{*}{ Выборка } & \multirow{2}{*}{$\mathbf{R} \mathbf{R}$} & \multirow{2}{*}{ Метод анализ } & \multicolumn{4}{|c|}{ Анализируемые факторы } \\
\hline & & & & Инструмент & Компания & Отрасль & Макро \\
\hline $\begin{array}{l}\text { Альтман и } \\
\text { Кишор } \\
\text { (Altman, } \\
\text { Kishore, } \\
\text { 1996) }\end{array}$ & $\begin{array}{l}696 \\
\text { облигаций } \\
(1978-1995)\end{array}$ & RAD & $\left|\begin{array}{ll}\text { Однофакторная } \\
\text { регрессия } \\
\text { уровне } \\
\text { инструмента }\end{array}\right|$ & Да & Нет & Да & Нет \\
\hline \multirow{2}{*}{$\begin{array}{l}\text { Изворски } \\
\text { (Izvorski, } \\
\text { 1997) }\end{array}$} & \multirow{2}{*}{$\begin{array}{l}281 \\
\text { облигация } \\
\text { (1983-1993) }\end{array}$} & \multirow[t]{2}{*}{ RAR } & \begin{tabular}{|ll} 
Регрессия на \\
уровне \\
инструмента
\end{tabular} & Да & Да & Да & Нет \\
\hline & & & \begin{tabular}{|lr} 
Регрессия \\
уровне отрасли
\end{tabular} & & - & Да & Да \\
\hline $\begin{array}{ll}\text { Ху } \\
\text { Перраудин } \\
\text { (Нu, }\end{array}$ & $\begin{array}{l}1541 \\
\text { облигаций } \\
(1982-1999)\end{array}$ & RAR & \begin{tabular}{|ll} 
Регрессия & на \\
уровне \\
инструмента
\end{tabular} & Да & Нет & Да & Нет \\
\hline
\end{tabular}

27 Отсрочка банкротства - это показатель, характеризующий период между наступлением неплатежеспособности компании и дефолтом, что связано с особенностями законодательства США о банкротстве. 


\begin{tabular}{|c|c|c|c|c|c|c|c|}
\hline $\begin{array}{l}\text { Perraudin, } \\
\text { 2002) }\end{array}$ & $\begin{array}{l}1422 \\
\text { облигаций } \\
(1971-1999)\end{array}$ & RAD & \begin{tabular}{|l} 
Регрессия на \\
уровне \\
инструмента
\end{tabular} & a Да & Нет & Да & Нет \\
\hline \multirow{2}{*}{$\begin{array}{l}\text { Ачария } \\
\text { (Acharya } \\
\text { and } \\
\text { al.,2003) }\end{array}$} & \multirow{2}{*}{$\begin{array}{l}645 \\
\text { облигаций } \\
(1982-1999)\end{array}$} & $\begin{array}{l}\text { RAD } \\
\text { RAR }\end{array}$ & $\begin{array}{l}\text { Регрессия на } \\
\text { уровне } \\
\text { инструмента }\end{array}$ & a Да & Да & Да & Да \\
\hline & & $\begin{array}{l}\text { RAD } \\
\text { RAR }\end{array}$ & $\begin{array}{l}\text { Регрессия на } \\
\text { уровне отрасли }\end{array}$ & $\mathrm{a}_{-}$ & - & Да & Да \\
\hline $\begin{array}{l}\text { Альтман } \\
\text { (Altman } \\
\text { and al., } \\
\text { 2005) }\end{array}$ & $\begin{array}{l}\text { Около } 1300 \\
\text { облигаций } \\
(1982-2001)\end{array}$ & RAD & $\begin{array}{l}\text { Регрессия на } \\
\text { уровне } \\
\text { экономики } \\
\text { страны }\end{array}$ & $\mathrm{a}$ & - & - & Да \\
\hline \begin{tabular}{|l|} 
Ковитц и \\
Хан \\
(Covitz, \\
Han, 2004)
\end{tabular} & $\begin{array}{l}1350 \\
\text { облигаций, } \\
\text { (1983-2002) }\end{array}$ & RAD & $\begin{array}{l}\text { Регрессия на } \\
\text { уровне } \\
\text { инструмента }\end{array}$ & Да & Да & Да & Да \\
\hline $\begin{array}{l}\text { Варма } \\
\text { (Varma and } \\
\text { al., 2004) }\end{array}$ & $\begin{array}{l}\text { Около } 1500 \\
\text { облигаций и } \\
\text { кредитов }\end{array}$ & RAD & $\begin{array}{l}\text { Сведение } \\
\text { таблицы } \\
\text { одному фактору } \\
\text { Регрессия } \\
\text { уровне } \\
\text { инструмента }\end{array}$ & $\begin{array}{l}\text { в } \\
\text { o } \\
y^{2}\end{array}$ & Да & Да & Да \\
\hline \begin{tabular}{|l|} 
Гуптон \\
(Gupton,20 \\
05)
\end{tabular} & $\begin{array}{l}3026 \\
\text { облигаций, } \\
\text { кредитов и } \\
\text { привилегиро } \\
\text { ванных } \\
\text { акций } \\
\end{array}$ & RAD & $\begin{array}{l}\text { Регрессия на } \\
\text { уровне } \\
\text { инструмента }\end{array}$ & Да & Да & Да & Да \\
\hline \multirow{2}{*}{$\begin{array}{l}\text { Джейкобс } \\
\text { (Jacobs, } \\
2010)\end{array}$} & \multirow{2}{*}{$\begin{array}{l}3902 \\
\text { облигаций и и } \\
\text { кредитов } \\
(1985-2006)\end{array}$} & \multirow{2}{*}{ RAD } & $\begin{array}{l}\text { Обобщенная } \\
\text { линейная } \\
\text { модель } \\
\text { уровне } \\
\text { инструмента } \\
\end{array}$ & a Да & Да & Да & Да \\
\hline & & & $\begin{array}{l}\text { Обобщенная } \\
\text { линейная } \\
\text { модель } \\
\text { уровне } \\
\text { эмитента } \\
\end{array}$ & a Да & Да & Да & Да \\
\hline
\end{tabular}

RAD - ставка восстановления на момент дефолта (recovery at default),

RAR - ставка восстановления на момент завершения банкротства (recovery at resolution).

Одной из наиболее ранних работ, посвященных моделированию ставки восстановления, является работа Изворски (Izvorski, 1997), вышедшая в серии научных публикаций Международного валютного фонда. В качестве исходной модели автор использует логит-модель. Преимуществом логит-модели является возможность ограничить объясняемую переменную интервалом $[0 ; 1]$, в котором, как правило, находится ставка восстановления. Автор оценивает модель по выборке из 153 дефолтов облигаций корпоративных заемщиков США, произошедших в период с 1983 по 1993 год.

В данном исследовании ставка восстановления рассчитывалась, как отношение суммы восстановления по облигации, по которой произошел дефолт, к рыночной стоимости наиболее близкой к ней по сроку погашения безрисковой облигации. В основную модель 
вошло восемь объясняющих переменных: финансовый рычаг, устаревание основных активов, темп роста в отрасли, индекс концентрации Херфиндаля, бинарный индикатор проведения судебной процедуры банкротства, уровень старшинства, спред доходности государственных облигаций и краткосрочная доходность. Статистически значимыми факторами являются старшинство в структуре долговых обязательств компании, темп роста в отрасли и тип реструктуризации, проводимой после наступления дефолта. Влияние показателей уровня старшинства и роста по отрасли на ставку восстановление положительно. Проведение судебной процедуры банкротства отрицательно сказывается на ставке восстановления.

Коэффициент детерминации равен 0,25 . С точки зрения набора используемых в модели факторов автор во многом предопределил дальнейшие развитие моделей прогнозирования ставки восстановления.

В своей работе Альтман (Altman et al., 2005) оценивает линейную регрессионную модель для агрегированной ставки восстановления. Агрегированная ставка восстановления рассчитывается как взвешенная по рыночной стоимости дефолтных облигаций сумма значений индивидуальных ставок восстановления. Модель с наивысшим значением коэффициента детерминации $\left(\mathrm{R}^{2}=0,87\right)$ включает в себя три фактора: логарифм средневзвешенного уровня дефолта по высокодоходным облигациям, изменение средневзвешенного уровня дефолта по высокодоходным облигациям и суммарную рыночную стоимость высокодоходных облигаций, обращающихся на рынке. Автор проверяет возможность улучшения модели за счет включения таких макроэкономических показателей, как рост ВВП, изменение темпа роста ВВП, годовая доходность по индексу $\mathrm{S} \& \mathrm{P} 500$ и годовое изменение по данному индексу. Однако при включении показателей, описывающих предложение высокодоходных облигаций, прочие макроэкономические показатели не имеют статистически значимого влияния на ставку восстановления. Однако значимость эмпирической проверки данной многофакторной модели ограничена, поскольку статистическая выборка состоит всего из 20 наблюдений.

В своей работе Ачария (Acharya et al., 2003) вслед за работой Изворски (Izvorski, 1997) продолжает исследование зависимости ставки восстановления от характеристик отрасли, в которой компания осуществляет деятельность.

В данной модели авторы рассчитывают ставку восстановления двумя способами. Первый способ состоит в расчете ставки восстановления на основе цены обязательства через месяц после наступления дефолта по отношению к номиналу облигации. Второй способ состоит в расчете ставки восстановления на основе восстановления, полученного по окончании процедуры банкротства. По причине того что время между наступлением дефолта и окончанием процедуры банкротства для различных компаний значительно отличается, авторы корректируют исходные данные с помощью поправочного коэффициента. Данный коэффициент показывает отношение индекса высокодоходных облигаций в момент наступления дефолта к индексу высокодоходных облигаций в момент завершения процедуры банкротства.

Авторы используют базу данных S\&P Credit Pro 4, состоящую из данных по дефолтам, произошедшим по американским корпоративным облигациям и кредитам в период с 1981 по 1999 годы. Размер выборки составляет 186 наблюдений в случае использования в качестве зависимой переменной ставку восстановления на момент дефолта и 711 наблюдений - в случае использования ставки восстановления на момент завершения процедуры банкротства. Коэффициент детерминации базовых моделей ${ }^{28}$ составляет 0,52 и $0,58-$ в зависимости от способа расчета ставки восстановления.

Статистически значимыми факторами в модели, в которой объясняемой переменной является ставка восстановления на момент дефолта, являются старшинство, рентабельность продаж, финансовый рычаг, волатильность доходности акций, индекс концентрации Херфиндаля и бинарный коэффициент, учитывающий принадлежность компании к отрасли

\footnotetext{
${ }^{28}$ Спецификация модели выбрана на основе максимального значения коэффициента детерминации.
} 
коммунального хозяйства. В модели, в которой объясняемой переменной является ставка восстановления на момент завершения процедуры банкротства, статистически значимыми факторами оказались старшинство, продолжительность банкротства, тип обеспечения, бинарная переменная, принимающая значение «1», когда средняя доходность в отрасли снижается за предшествующий год более чем на $30 \%$, и «0»- в обратном случае, медианное значение показателя Q по отрасли, медианное значение показателя ликвидности по отрасли, рассчитанное на основе показателя срочной ликвидности, а также бинарный коэффициент, учитывающий принадлежность компании к отрасли коммунального хозяйства

Модель LossCalc разработана Грегом Гуптоном и Роджером Стейном (Gupton, Stein, 2002) в 2002 году для прогнозирования ставки восстановления по кредитам, корпоративным облигациям и привилегированным акциям. В модели используется девять объясняющих факторов: тип долгового обязательства (облигация, кредит, привилегированная акция), уровень старшинства, относительное старшинство, финансовый рычаг, среднее по отрасли значение ставки восстановления, индикатор банковской отрасли, вероятность дефолта и индекс цен облигаций компаний-банкротов Moody's, средний уровень дефолта по спекулятивным ценным бумагам, изменение в индексе ведущих экономических индикаторов.

В данной модели объясняемой переменной является оценка ставки восстановления, рассчитанная на основе рыночной цены, по которой инвесторы готовы приобрести данную корпоративную облигацию, через месяц после объявления дефолта. Авторы моделируют распределение ставки восстановления посредством $\beta$-распределения ${ }^{29}$, а затем трансформируют $\beta$-распределение в нормальное распределение с помощью математического преобразования с целью применения в регрессионном анализе.

Влияние каждой группы факторов на ставку восстановления различно и в убывающей последовательности распределено следующим образом: тип долгового обязательства и старшинство; макроэкономические факторы; отраслевые факторы; и специфические для компании факторы и структура капитала. Все перечисленные объясняющие факторы статистически значимы, однако показатели качества регрессионной модели авторы не раскрывают.

\section{Оценка ставки восстановления на основе модели Р. Мертона}

Базовая модель Р. Мертона (Merton, 1974) опирается на теорию структуры капитала компании, разработанную Модильяни и Миллером (Modigliani, Miller, 1958), и модель ценообразования опционов Блэка - Шоулза (Black, Scholes, 1973).

Основной результат, полученный Р. Мертоном, состоит в том, что стоимость компании, финансирующей свои активы за счет собственного и заемного капитала, равна стоимости опциона колл на покупку активов компании по цене исполнения, равной дисконтированной стоимости ее обязательств.

Выплаты владельцам компании (покупателям опциона) равны рыночной стоимости активов, уменьшенной на сумму обязательств. Выплаты, в принципе, не ограничены сверху, а их максимальные потери сводятся к рыночной стоимости принадлежащих им акций, что в точности соответствует длинной позиции по опциону колл. Если рыночная стоимость активов опускается ниже дисконтированной стоимости обязательств, акционерам выгодно не исполнять опцион и передать свои права на активы компании кредиторам, в противном случае акционерам выгодно исполнить опцион и погасить обязательства компании.

Напротив, выигрыш кредитора ограничивается сверху величиной процентов по обязательства компании, но его потери при банкротстве компании составляют в наихудшем случае основную сумму обязательств. Предоставление компании займа при наличии кредитного риска рассматривается в модели Мертона как приобретение кредиторами активов компании при одновременной продаже ее владельцам опциона на выкуп этих активов. Такая

\footnotetext{
${ }^{29}$ Использование $\beta$-распределения позволяет учесть бимодальность распределения ставки восстановления и ее ограниченность на интервале [0;1].
} 
структура выплат соответствует короткой позиции по опциону пут.

Мертон применяет модель Блэка - Шоулза для оценки стоимости опциона колл, предполагая верность всех допущений, лежащих в ее основе:

$$
E=V \cdot N\left(d_{1}\right)-D \cdot N\left(d_{2}\right)
$$

где

$$
\begin{aligned}
& d_{1}=\frac{\ln \left(\frac{V}{D}\right)+\sigma^{2} \cdot \frac{T}{2}}{\sigma^{*} \sqrt{T}} \\
& d_{2}=d_{1}-\sigma^{*} \sqrt{T}
\end{aligned}
$$

$E$ - рыночная стоимость компании (капитализация);

$N(z)$ - функция вероятности для стандартного нормального распределения;

$T$ - срок погашения обязательств компании;

$D$ - текущая стоимость обязательств компании со сроком погашения $T$, рассчитанная путем дисконтирования по безрисковой процентной ставке;

$V$ - рыночная стоимость активов компании;

$\sigma$ - волатильность стоимости активов компании.

В модели Мертона текущая рыночная стоимость обязательств компании равна разности между стоимостью активов и собственного капитала: $D=V-E$. Параметр $N\left(d_{1}\right)$ является частной производной рыночной стоимости акций $(E)$ по рыночной стоимости активов компании $(V)$, т. е. дельтой опциона колл. Параметр $N\left(d_{2}\right)$ отражает вероятность того, что цена исполнения для опциона колл будет превышена в момент времени $T$. Но это же будет и вероятностью того, что дефолт не наступит; следовательно, вероятность дефолта будет равна:

$$
P D=1-N\left(d_{2}\right)
$$

В случае дефолта кредиторам выплачивается только некоторая часть их требований, размер которой определяется как:

$$
(1-L G D) D \text { или } R R \cdot D \text {, }
$$

где:

$R R$ - ставка восстановления;

$L G D$ - доля потерь при дефолте;

$D$ - текущая стоимость обязательств компании со сроком погашения $T$, рассчитанная путем дисконтирования по безрисковой процентной ставке.

Рыночную стоимость обязательств компании можно представить как математическое ожидание выплат по обязательствам в двух случаях: при дефолте и продолжении деятельности компании:

(5) $\quad V-E=(1-P D) D+P D R R D$.

Подставляя в (5) рыночную стоимость компании $E$ в соответствии с (2), получаем:

(6) $\quad V\left(1-N\left(d_{1}\right)\right)+D N\left(d_{2}\right)=N\left(d_{2}\right) D+\left(1-N\left(d_{2}\right)\right) R R D$.

Откуда следует:

$$
R R=\frac{1-N\left(d_{1}\right)}{1-N\left(d_{2}\right)} \cdot \frac{V}{D},
$$

где:

$$
\begin{aligned}
& d_{1}=\frac{\ln \left(\frac{V}{D}\right)+\sigma^{2} \cdot \frac{T}{2}}{\sigma^{*} \sqrt{T}} \\
& d_{2}=d_{1}-\sigma^{*} \sqrt{T}
\end{aligned}
$$

Из уравнения (7) следует, что ставка восстановления является эндогенной величиной, определяемой на основе таких характеристик компании, как рыночная стоимость активов $(V)$, их волатильность $(\sigma)$, коэффициент финансового рычага и срок погашения обязательств 
$(T)$.

Модель адекватно отображает экономическую взаимосвязь между ставкой восстановления и ключевыми показателями деятельности компании и состоянием финансового рынка. Ставка восстановления находится в обратной зависимости от коэффициента финансового рычага, что подтверждается эмпирическими исследованиями [9]. Чем выше долговая нагрузка компании, тем меньше собственных средств компании обеспечивает ее обязательства перед кредиторами. Поэтому ставка восстановления в случае дефолта компании с меньшим финансовым рычагом выше, чем у аналогичной компании с более высоким коэффициентом финансового рычага.

Волатильность рыночной стоимости активов компании, являясь мерой общего риска, отражает системный и специфический риски. Поэтому связь между ставкой восстановления и волатильностью является обратной: чем больше общий риск, тем меньше ставка восстановления.

Главное преимущество расчета ставки восстановления на основе модели Мертона заключается в том, что ставка восстановления выводится на основе наблюдаемых на рынке котировок акций и коэффициента финансового рычага. Однако в основе модели Мертона лежит ряд нереалистичных предпосылок, что осложняет ее применение на практике. В частности в модели Мертона предполагается, что:

1. Компания-заемщик имеет только на один вид долговых обязательств облигации с нулевым купоном, при этом она не производит новых заимствований любого рода вплоть до полного погашения этих облигаций.

2. Дефолт по обязательствам может наступить только в момент наступления срока погашения облигаций.

3. Объявление дефолта по долговым обязательствам означает банкротство компании.

4. Промежуточные выплаты акционерам, такие, например, как дивиденды, не производятся до наступления срока исполнения долговых обязательств.

Также к недостаткам расчета ставки восстановления на основе Мертона необходимо отнести ряд нереалистичных предположений, лежащих в основе модели Блэка - Шоулса. В первую очередь допущение о том, что волатильность рыночной стоимости активов компании постоянна на протяжении срока погашения обязательств, а распределение рыночной стоимости активов компании соответствует нормальному распределению.

Ряд ученых работали над усовершенствованием структурной модели Мертона. Блэк и Кокс (Black, Cox, 1976), Жеске (Geske,1977) и Васичек (Vasicek, 1984) и другие предложили способы улучшения базовой модели Мертона за счет снятия одной или нескольких ее предпосылок. Так, Блэк и Кокс используют более сложную структуру капитала с субординированным долгом; Жеске вводит в свою модель купонные облигации; Васичек разделяет обязательства компании на краткосрочные и долгосрочные.

Базовая модель Мертона адекватно отражает экономические взаимосвязи между ставкой восстановления и показателями деятельности компании. Уточнение предпосылок, лежащих в ее основе, позволяет приблизить теоретическое обоснование к практическим условиям рынка. Благодаря теоретической согласованности и несущественным требованиям к исходным данным, базовая модель Мертона является перспективным способом оценки ставки восстановления.

\section{Заключение}

На основе обзора накопленного опыта измерения и прогнозирования ставки восстановления в настоящей статье систематизированы факторы, влияющие на ставку восстановления по корпоративным облигациям, и обобщены методы ее оценки, нашедшие наиболее широкое отражение в академических исследованиях. Объясняющие факторы выделены в четыре группы, и предшествующие исследования подтверждают значимость факторов из каждой группы в оценке ставки восстановления в зависимости от избранной 
модели и статистической выборки. Наиболее эффективная модель оценивается посредством выбора оптимальной комбинации факторов из всех четырех групп.

\section{Список литературы}

1. Acharya, V., Bharath, S., Srinivasan, A. (2003), Understanding the Recovery Rates of Defaulted Securities, http://papers.ssrn.com/sol3/papers.cfm?abstract_id=442901.

2. Altman, E., Kishore, V. (1996), Almost Everything You Wanted to Know About Recoveries on Defaulted Bonds, Financial Analysts Journal, 52 (1996) 57-64.

3. Altman, E., Brady, B., Resti, A., Sironi, A. (2001), Analyzing and Explaining Default Recovery Rates, ISDA Research Report, http://www.isda.org/c_and_a/pdf/Analyzing_Recovery_rates_010702.pdf.

4. Altman, E., Brady B., Resti, A., Sironi, A. (2005), The Link between Default and Recovery Rates: Theory, Empirical Evidence, and Implications, Journal of Business, 78 (2005) 22032227.

5. Black, F., Cox, J.C. (1976), Valuing Corporate Securities: Some Effects of Bond Indenture Provisions, Journal of Finance, 31 (1976) 351-367.

6. Black, F., Scholes, M. (1973), The Pricing of Options and Corporate Liabilities, Journal of Political Economics, 81 (1973), 637-659.

7. Covitz, D., Han, S. (2004), An Empirical Analysis of Bond Recovery Rates: Exploring a Structural View of Default, Federal Reserve Board Division of Research and Statistics, http://www.federalreserve.gov/pubs/feds/2005/200510/200510pap.pdf.

8. Franks, J., Torous, W. (2000), A Comparison of Financial Restructuring in Distressed Exchanges and Chapter 11 Reorganisations, Journal of Financial Economics, 35 (2000) 349-370.

9. Frye, J. (2000), Collateral damage detected: A Source of Systematic Credit Risk, Working paper of Federal Reserve Bank of Chicago, http://www.chicagofed.org/digital_assets/publications/risk_management_papers/sr_2000_15 .pdf.

10. Geske, R. (1977), The Valuation of Corporate Liabilities as Compound Options, Journal of Financial and Quantitative Analysis, 12 (1977) 541-552.

11. Gupton, G.M. (2005), Advancing Loss Given Default Prediction Models: How the Quiet Have Quickened, Economic Notes, 34 (2005) 185-230.

12. Gupton, G. M., Stein, R. M. (2002), LossCalcTM: Model for Predicting Loss Given Default, Moody's KMV, http://www.defaultrisk.com/_pdf6j4/losscalc_methodology.pdf.

13. Hamilton, D., Cantor, R., West, M. and Fowlie, K. (2002), Default and recovery rates of European Corporate Bond Issuers, 1985-2001, Moody's Investors Service Global Credit Research Special Comment.

14. Hamilton, D.T., Gupton, G.M., Berhault, A. (2001), Default and Recovery Rates of Corporate Bond Issuers: 2000, Moody’s Investors Service Global Credit Research Special Comment.

15. Hu, Yen-ting, Perraudin, W., (2002), The Dependence of recovery and defaults, Birkbeck College, http://www3.imperial.ac.uk/portal/pls/portallive/docs/1/43768.PDF.

16. Izvorski, I. (1997), Recovery Ratios and Survival Times for Corporate Bonds, Working Paper of International Monetary Fund, http://www.imf.org/external/pubs/ft/wp/wp9784.pdf.

17. Jacobs, M., Karagozoglu, A. (2010), Modeling Ultimate Loss-Given-Default on Bonds and Loans, http://www.defaultrisk.com/pp_recov101.htm.

18. Merton, R. (1974), On the Pricing of Corporate Debt: The Risk Structure of Interest Rates, Journal of Finance, 2 (1974) 449-471.

19. Modigliani, F.; Miller, M. (1958), The Cost of Capital, Corporation Finance and the Theory of Investment, American Economic Review, 48 (1958) 261-297.

20. Schuermann, T. (2004), What Do We Know About Loss Given Default? The Wharton 
Financial Institutions Center, http://fic.wharton.upenn.edu/fic/papers/04/0401.pdf.

21. VandeCastle, K. (1999), Recovering your money: Insights into losses from default, Standard and Poor's.

22. Varma, P., Cantor, R. (2004), Determinants of Recovery Rates on Defaulted Bonds and Loans for North American Corporate Issuers: 1983-2003, Moody's Investors Service Global Credit Research Special Comment.

23. Vasicek, O.A (1984), Credit Valuation, Moody's KMV Research Papers, http:/www.moodyskmv.com/research/files/wp/Credit_Valuation.pdf. 